\title{
A Case of Neuroschistosomiasis Presenting as Transverse Myelitis: The Importance of History Taking
}

\author{
Ahmad S. Matarneh ${ }^{1}$, Wafa Abdullah ${ }^{1}$, Adeel A. Khan ${ }^{1}$, Amna Sadiq ${ }^{2}$, Khalid Farooqui $^{1}$ \\ 1. Internal Medicine, Hamad Medical Corporation, Doha, QAT 2. Radiology, Hamad Medical Corporation, Doha, QAT
}

Corresponding author: Ahmad S. Matarneh, ahmadmatarneh99@gmail.com

\begin{abstract}
Neuroschistosomiasis is a rare manifestation of Schistosoma infection and can either manifest as cerebritis or with spinal cord involvement. We present a case of low back pain and lower limb weakness, which was initially managed as idiopathic transverse myelitis and later on found to have neuroschistosomiasis.

A 23-year-old Sudanese gentleman presented with a one-week history of low back pain, lower limb weakness, and urinary retention. An urgent MRI of the spine with contrast showed features suggestive of transverse myelitis. The patient was treated with intravenous methylprednisolone for five days, which showed significant improvement in his symptoms. One week later, the patient developed the same symptoms again. An urgent MRI spine showed an interval progression of MRI findings. Repeat history taking revealed a history of swimming many times in the river Nile. Serology was sent for Schistosoma and came positive with titer 1:1280. He was treated as neuroschistosomiasis with intravenous steroids for three days, followed by praziquantel for five days along with the steroids, after which he showed significant improvement in his lower limb weakness.
\end{abstract}

Spinal neuroschistosomiasis is one of the very rare complications of Schistosoma infection that should be kept in mind when dealing with unexplained myelopathy with a history of travel or origin from an endemic area. If not treated promptly, it can result in severe irreversible complications.

Review began 10/12/2020 Review ended 11/11/2020 Published 11/11/2020

() Copyright 2020 Matarneh et al. This is an open access article distributed under the terms of the Creative Commons Attribution License CC-BY 4.0., which permits unrestricted use, distribution, and reproduction in any medium, provided the original author and source are credited.
Categories: Internal Medicine, Neurology, Infectious Disease

Keywords: neuroschistosomiasis, schistosomiasis, transverse myelitis, helminthic

\section{Introduction}

Schistosomiasis is a helminthic disease and is considered a common parasitic infection in the Middle East [1]. Infection usually occurs after contact with the intermediate host, which are snails in freshwater, containing the eggs and parasite. Snails then release cercariae, the infectious form of the parasite, into the water that can affect hosts after penetrating the skin [2]. Neuroschistosomiasis is a rare manifestation of the disease. It can either involve the brain where it can cause cerebritis or involve the spinal cord [3]. In this case, we present a rare clinical scenario in which the patient presented with lower limb weakness and was found to have transverse myelitis secondary to neuroschistosomiasis and showed significant improvement after treatment.

\section{Case Presentation}

A previously healthy 23-year-old Sudanese gentleman presented to the hospital with a one-week history of low back pain, dull in character, occurring mainly at night associated with difficulty in urination and weakness in both legs for three days. Lower limb weakness was symmetrical and progressed over one day till he became unable to move his legs. He denied weakness in arms or any disturbance in sensations. There was no recent history of fever, sore throat, cough, night sweats, weight loss, or trauma to the back. No personal or family history of similar conditions was reported. The patient was a non-smoker, and there was no history of alcohol abuse. He was living in Qatar, and his last travel to Sudan was eight months ago. He worked as a guard and mentioned a history of lifting heavy objects at work.

On examination, the patient had normal vital signs. Neurological examination was remarkable for hypertonia in both lower limbs. Power was $4 / 5$ in proximal muscles and $1 / 5$ in distal muscles. He had exaggerated knee jerk reflexes bilaterally but normal ankle jerk reflexes. Plantar reflexes were flexor bilaterally. The sensory and cerebellar examination was normal. Back examination revealed tenderness over the sacral area. Cardiac, respiratory, and abdominal examinations were normal. Complete blood count, urea, creatinine, electrolytes, C-reactive protein, procalcitonin, vitamin B12, folic acid, and thyroid function tests were normal (Table 1). 


\section{Cureus}

\begin{tabular}{|c|c|c|}
\hline Test & Result & Reference Range \\
\hline WBC count & $4.9 \times 10^{\wedge} 6 / \mathrm{ul}$ & $4.5-5.5 \times 10^{\wedge} 6 / \mathrm{ul}$ \\
\hline $\mathrm{Hgb}$ & $14.3 \mathrm{gm} / \mathrm{dl}$ & $13-17 \mathrm{gm} / \mathrm{dl}$ \\
\hline Urea & $2.90 \mathrm{mmol} / \mathrm{L}$ & $2.8-8.1 \mathrm{mmol} / \mathrm{L}$ \\
\hline Creatinine & $78.0 \mathrm{umol} / \mathrm{L}$ & $62-106 \mathrm{umol} / \mathrm{L}$ \\
\hline Sodium & $139.0 \mathrm{mmol} / \mathrm{L}$ & $136-145$ mmol/L \\
\hline Potassium & $3.90 \mathrm{mmol} / \mathrm{L}$ & $3.5-5.1 \mathrm{mmol} / \mathrm{L}$ \\
\hline Calcium & $2.34 \mathrm{mmol} / \mathrm{L}$ & $2.15-2.50 \mathrm{mmol} / \mathrm{L}$ \\
\hline AST & $49.0 \mathrm{U} / \mathrm{L}$ & $0-40 \mathrm{U} / \mathrm{L}$ \\
\hline ALT & $21.0 \mathrm{U} / \mathrm{L}$ & $0-41 \mathrm{U} / \mathrm{L}$ \\
\hline ALP & $65.0 \mathrm{U} / \mathrm{L}$ & $40-129 \mathrm{U} / \mathrm{L}$ \\
\hline CRP & $0.5 \mathrm{mg} / \mathrm{dl}$ & $0.0-5.0 \mathrm{mg} / \mathrm{dl}$ \\
\hline Lactic acid & $1.0 \mathrm{mmol} / \mathrm{L}$ & $0.5-2.2 \mathrm{mmol} / \mathrm{L}$ \\
\hline Procalcitonin & $0.31 \mathrm{ng} / \mathrm{ml}$ & $<0.5 \mathrm{ng} / \mathrm{mL}$ \\
\hline Vitamin B12 & $196.0 \mathrm{pmol} / \mathrm{L}$ & $145-596 \mathrm{pmol} / \mathrm{L}$ \\
\hline ANA & Negative & \\
\hline C3 & $0.82 \mathrm{gm} / \mathrm{dl}$ & $0.8-1.8 \mathrm{gm} / \mathrm{dl}$ \\
\hline C4 & $0.14 \mathrm{gm} / \mathrm{dl}$ & $0.1-0.40 \mathrm{gm} / \mathrm{dl}$ \\
\hline
\end{tabular}

\section{TABLE 1: Basic laboratory investigations}

WBC: white blood cell, Hgb: hemoglobin, AST: aspartate aminotransferase, ALT: alanine aminotransferase, ALP: alkaline phosphatase, CRP: Creactive protein, ANA: anti-nuclear antibody

Autoimmune profile, blood culture, serology for brucella, syphilis, hepatitis B, Hepatitis C, and HIV were negative. The chest X-ray was normal. An urgent MRI of the spine with contrast showed a T2 bright signal of a long segment of the lower dorsal spinal cord and conus medullaris (mainly central and bilateral intramedullary) with focal T12/L1 levels faint postcontrast enhancement suggestive of transverse myelitis (Figure 1). 


\section{Cureus}

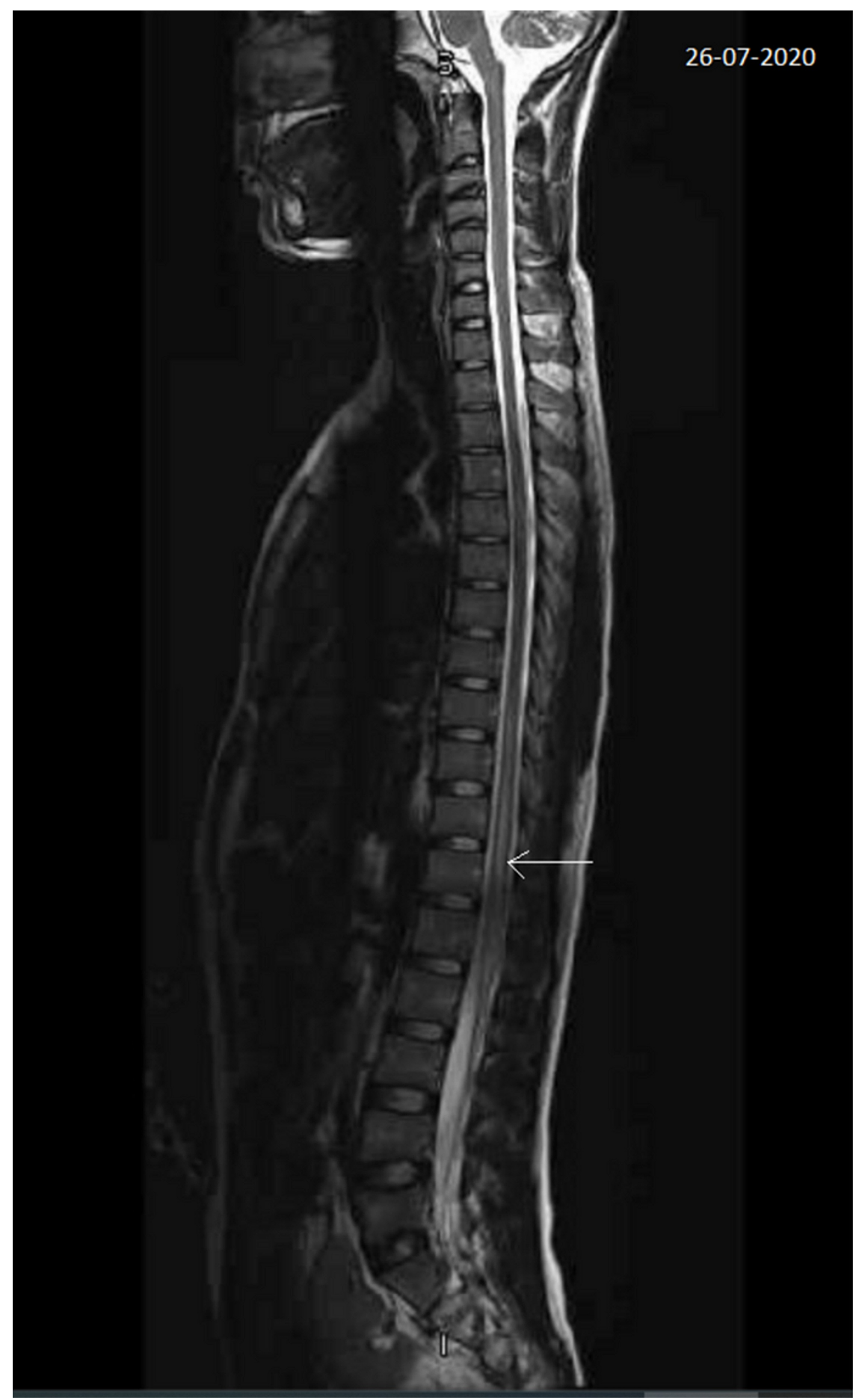

FIGURE 1: T2 bright signal of the long segment of lower dorsal spinal cord and conus medullaris (mainly central and bilateral intramedullary) with focal T12/L1 levels faint postcontrast enhancement suggestive of transverse myelitis

Cerebrospinal fluid (CSF) analysis showed 201 white blood cells (WBCs) with 95\% lymphocytes. Glucose was $4.52 \mathrm{mmol} / \mathrm{L}$ and proteins $0.45 \mathrm{gm} / \mathrm{L}$ (Table 2). The patient was diagnosed with idiopathic transverse myelitis and started on intravenous (IV) methylprednisolone for five days, which resulted in significant improvement in his symptoms. He was then transferred to a rehabilitation facility. 


\section{Cureus}

\begin{tabular}{|c|c|c|}
\hline Test & Result & Reference Range \\
\hline Colour & Colourless & -- \\
\hline White blood cells & $201 / u L$ & $0-5 / \mathrm{uL}$ \\
\hline Red blood cells & $15 / u L$ & $0-2 / u l$ \\
\hline Lymphocytes & $95 \%$ & $40-80 \%$ \\
\hline Monocytes & $2 \%$ & $15-45 \%$ \\
\hline Glucose & $4.52 \mathrm{mmol} / \mathrm{L}$ & $2.22-03.89 \mathrm{mmol} / \mathrm{L}$ \\
\hline Proteins & $0.45 \mathrm{gm} / \mathrm{L}$ & $0.15-0.45 \mathrm{gm} / \mathrm{L}$ \\
\hline AFB smear & Negative & \\
\hline Oligoclonal bands & Negative & \\
\hline Viral panel & Negative & \\
\hline Culture & Negative & \\
\hline
\end{tabular}

\section{TABLE 2: CSF analysis}

CSF: cerebrospinal fluid, AFB: acid-fast bacillus

One week later, the patient developed the same symptoms again. An urgent MRI spine showed the progression of his disease (Figures $2 a, 2 b$ ). A repeat CSF examination showed 54 WBCs with 91\% lymphocytes (Table 3).

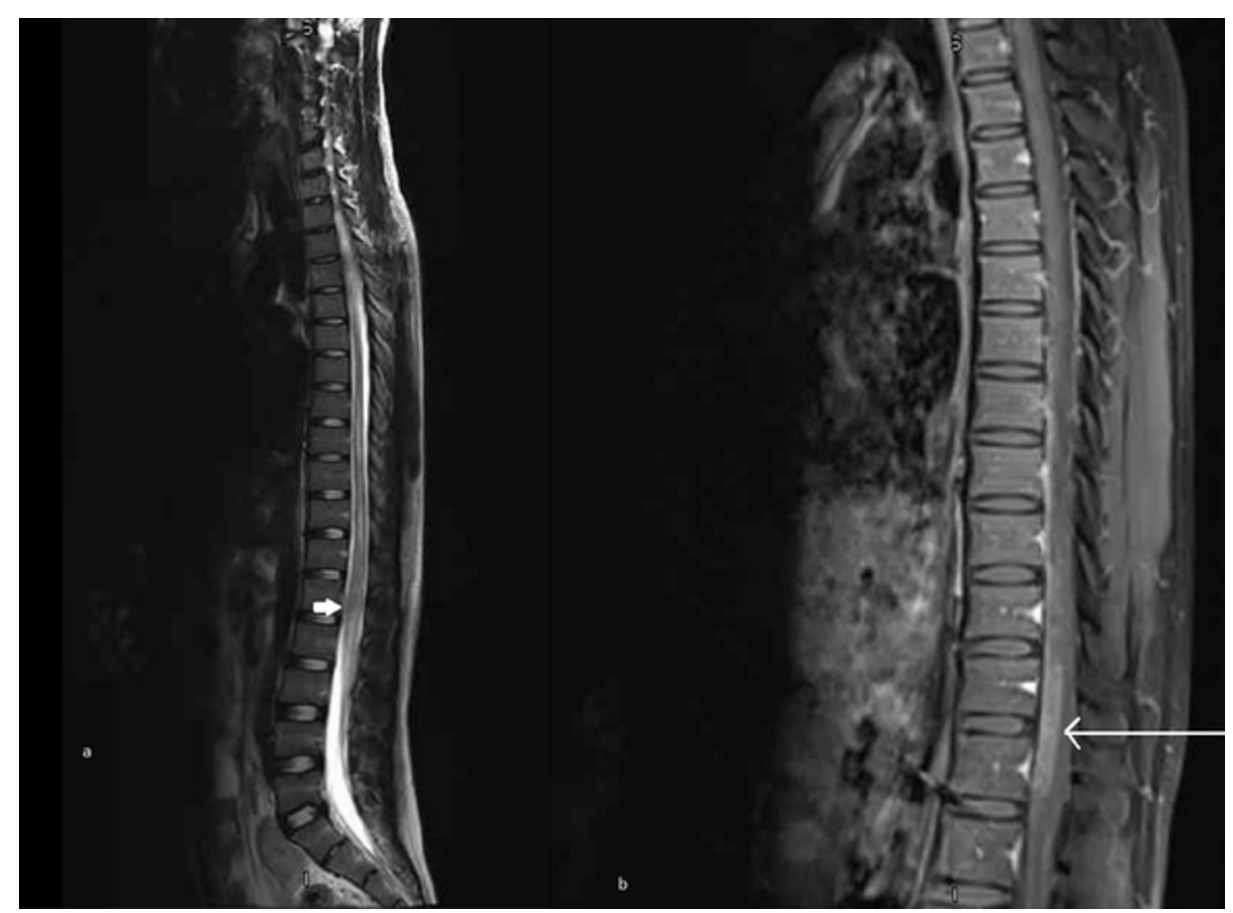

FIGURE 2: MRI thoracolumbar spine with contrast showing interval increase in intramedullary T2 enhanced signals. There is also a prominent enhancement of cauda equina root. Oedema of conus (arrow in image a). New patchy enhancement noted in the spinal cord at T10T11 level (image b) 


\section{Cureus}

\begin{tabular}{|c|c|c|}
\hline Test & Result & Reference Range \\
\hline Colour & Colourless & -- \\
\hline White blood cells & $54 / \mathrm{uL}$ & $0-5 / \mathrm{uL}$ \\
\hline Red blood cells & $3 / \mathrm{uL}$ & $0-2 / u l$ \\
\hline Lymphocytes & $91 \%$ & $40-80 \%$ \\
\hline Monocytes & $5 \%$ & $15-45 \%$ \\
\hline Glucose & $2.99 \mathrm{mmol} / \mathrm{L}$ & $2.22-03.89 \mathrm{mmol} / \mathrm{L}$ \\
\hline Proteins & $1.36 \mathrm{gm} / \mathrm{L}$ & $0.15-0.45 \mathrm{gm} / \mathrm{L}$ \\
\hline AFB smear & Negative & \\
\hline Oligoclonal bands & Negative & \\
\hline Viral panel & Negative & \\
\hline Culture & Negative & \\
\hline
\end{tabular}

\section{TABLE 3: CSF analysis second admission}

CSF: cerebrospinal fluid, AFB: acid-fast bacillus

CT chest showed tree in bud appearance, raising suspicion of pulmonary tuberculosis. However, acid-fast bacillus (AFB) smear and polymerase chain reaction (PCR) from sputum and bronchoalveolar lavage were negative. CT abdomen and pelvis were unremarkable. When retaking history, he mentioned swimming frequently in the river Nile. Given the high incidence of Schistosoma in swimmers, serology for Schistosoma was sent and came positive with titer 1:1280. Hence, he was diagnosed with neuroschistosomiasis and started on intravenous steroids for three days, followed by praziquantel for five days along with the steroids, after which he showed significant improvement in his lower limb weakness. He was transferred to the rehabilitation center and kept on oral steroids for six weeks with good tolerance to medications; he continued to improve.

\section{Discussion}

Schistosomiasis is a rare helminthic disease caused by Schistosoma flukes that can affect multiple organs, including the liver, intestines, lungs, urinary bladder, brain, and spinal cord. There are several known types of Schistosoma, namely, S. haematobium, S. intercalatum, S. japonicum, S. mansoni, and S. mekongi [4]. It is regarded as the second most common tropical disease [5]. Neuroschistosmiasis is usually a rare presentation resulting from the embolization of the organism's eggs through the vasculature until it lands in the central nervous system. It is divided into cerebral Schistosoma, which occurs when S. japonicum reaches the brain causing encephalitis causing symptoms of headache, seizures, altered mentation or the spinal schistosomiasis resulting from S. mansoni (and less commonly S. haematobium) where it can cause myelitis with symptoms of weakness, back pain and urine retention (Poster: Elsbernd P, Lago K, Calvano T, Sladky J. Complete Neurologic Recovery after Acute Cauda Equina Syndrome due to Neuroschistosomiasis. AAN 70th Annual Meeting; April 26, 2018). After the eggs of the organism reach the central nervous system, they mature into adult forms. Schistosoma eggs usually induce a local eosinophilic inflammation resulting from the release of proteolytic enzymes. The resultant inflammation causes damage and granuloma formation, and eventually fibrosis and demyelination of the surrounding structures [6].

A high index of clinical suspicion based on epidemiological stratification is required to make the diagnosis of neuroschistosomiasis. MRI is the imaging modality of choice to diagnose central nervous system (CNS) involvement and it can detect changes consistent with acute myelitis and spinal cord compression secondary to granuloma $[7,8]$. A definite diagnosis is made by tissue biopsy. Serology is a sensitive test for the diagnosis, but with high false-positive rates, they are sometimes considered un-reliable, however, positive test results with high titers (>1:160) are considered significant [6,9].

After establishing the diagnosis, rapid treatment should always be sought as it has a significant benefit in improving the outcome. Steroids are usually started before praziquantel to decrease the inflammation that might result from the cytotoxic effect of praziquantel on the organism [10]. Praziquantel acts by increasing the membrane permeability to calcium, thereby causing tetanic contractions and paralyzing the organism [11]. Moreover, it acts only on the mature adult worms and not the larval form rendering it ineffective in the early stages of infection [12]. Other lines of treatment include artemisinin, of limited efficacy, and 
oxamniquine, which is only effective on S. mansoni [13].

Our patient was initially diagnosed with transverse myelitis and received IV steroids for five successive days with significant improvement. However, his symptoms worsened shortly after stopping the steroids. On repeated history taking, the patient reported a history of swimming in freshwater in Sudan, which, combined with high titers of antibodies, raised suspicion of neuroschistosomiasis as a cause.

\section{Conclusions}

Spinal neuroschistosomiasis is one of the very rare presentations of Schistosoma infection that should be kept in mind when dealing with unexplained myelopathy with a history of travel or origin from an endemic area. If not treated promptly, it can result in severe irreversible complications. Treatment with steroids before initiating praziquantel can help in decreasing the risk of disease progression, improving morbidity and overall outcome.

\section{Additional Information \\ Disclosures}

Human subjects: Consent was obtained by all participants in this study. Medical Research Center - Hamad Medical Corporation issued approval MRC -04-20-865. Conflicts of interest: In compliance with the ICMJE uniform disclosure form, all authors declare the following: Payment/services info: All authors have declared that no financial support was received from any organization for the submitted work. Financial relationships: All authors have declared that they have no financial relationships at present or within the previous three years with any organizations that might have an interest in the submitted work. Other relationships: All authors have declared that there are no other relationships or activities that could appear to have influenced the submitted work.

\section{References}

1. Clerinx J, Van Gompel A: Schistosomiasis in travellers and migrants . Travel Med Infect Dis. 2011, 9:6-24. 10.1016/j.tmaid.2010.11.002

2. Colley DG, Bustinduy AL, Secor WE, King CH: Human schistosomiasis. Lancet. 2014, 383:2253-2264. 10.1016/S0140-6736(13)61949-2

3. Ferrari TC: Involvement of central nervous system in the schistosomiasis. Mem Inst Oswaldo Cruz. 2004, 99:59-62. 10.1590/s0074-02762004000900010

4. Nelwan ML: Schistosomiasis: life cycle, diagnosis, and control. Curr Ther Res. 2019, 91:5-9. 10.1016/i.curtheres.2019.06.001

5. Li Y, Ross AG, Hou X, Lou Z, McManus DP: Oriental schistosomiasis with neurological complications: case report. Ann Clin Microbiol Antimicrob. 2011, 10:5. 10.1186/1476-0711-10-5

6. Al-Abdulwahhab AH, Al-Sharydah AM, Al-Suhibani SS, Al-Jubran SA, Al-Haidey AK, Al-Hifzi AI, Al-Issawi W: Neuroschistosomiasis mimicking lower back pain: case report of a rare differential diagnosis in a pediatric patient. Patient Saf Surg. 2018, 12:28. 10.1186/s13037-018-0175-z

7. Ferrari TC, Moreira PR: Neuroschistosomiasis: clinical symptoms and pathogenesis. Lancet Neurol. 2011, 10:853-864. 10.1016/S1474-4422(11)70170-3

8. Llenas-García J, Guerra-Vales JM, Alcalá-Galiano A, et al.: Cerebral neuroschistosomiasis: a rare clinical presentation and review of the literature. BMJ Case Rep. 2009, 2009:bcr04.2009.1787. 10.1136/bcr.04.2009.1787

9. Kinkel HF, Dittrich S, Bäumer B, Weitzel T: Evaluation of eight serological tests for diagnosis of imported schistosomiasis. Clin Vaccine Immunol. 2012, 19:948-953. 10.1128/CVI.05680-11

10. Gray DJ, Ross AG, Li YS, McManus DP: Diagnosis and management of schistosomiasis. BMJ. 2011, 342:d2651. 10.1136/bmj.d2651

11. Vale N, Gouveia MJ, Rinaldi G, Brindley PJ, Gärtner F, da Costa JM: Praziquantel for schistosomiasis: singledrug metabolism revisited, mode of action, and resistance. Antimicrob Agents Chemother. 2017, 61:e02582 16. 10.1128/AAC.02582-16

12. Xiao SH, Sun J, Chen MG: Pharmacological and immunological effects of praziquantel against Schistosoma japonicum: a scoping review of experimental studies. Infect Dis Poverty. 2018, 7:9. 10.1186/s40249-0180391-x

13. Sayed AA, Simeonov A, Thomas CJ, Inglese J, Austin CP, Williams DL: Identification of oxadiazoles as new drug leads for the control of schistosomiasis. Nat Med. 2008, 14:407-412. 10.1038/nm1737 